\title{
HABITABILIDAD DE PERTENENCIA
}

EPISTEMUS

ISSN: 2007-8196 (electrónico)

ISSN: 2007-4530 (impresa)

Carlos Vicente Tostado Cosío

Recibido: 12 de septiembre de 2016,

Aceptado: 30 de noviembre del 2016

Autor de Correspondencia:

Dr. Carlos Vicente Tostado Cosío

Correo: cartoscos@gmail.com
Universidad de Sonora Dr. en Arquitectura, Diseño y Urbanismo. Docente en el

Departamento de Arquitectura y Diseño / Correo:cartoscos@gmail.com

\section{Resumen}

Se habrán de registrar los antecedentes y recopilar la documentación relativa al crecimiento de la mancha urbana de finales del pasado siglo, para comprender las diferentes características de la obra transformada en espacios y de forma alguna, también, percibir los abandonos de costumbres heredadas de la visión humana que, debiendo recuperar su objetividad y sentido de identidad ya inadvertida en el tiempo, se ha de procurar su recate desde la individualidad del colectivo social.

Deliberadamente se asume éste propósito, al mostrar las múltiples facetas en las que la vivienda aparenta solo responder a su temporal y subjetivo suceder histórico, que en el discernimiento de la percepción generacional de apariencia, empleada por Lambert (1764), al apropiarse o adoptar las modas, costumbres, diseños y materiales de otras regiones, se han constituido en las variables del entender la vida de los habitantes, migrantes y posesionarios de eventualidad de los espacios del ecosistema en la ciudad; hoy concebida, como el gran hábitat humano.

El termino masificación o, adaptación de un grupo o de un fenómeno a las características de las masas, término adoptado a lo señalado reiteradamente por la vivienda contemporánea, forma parte de un fenómeno al que Ricoeur (1997, con una mirada retrospectiva, trata el papel que juega la comprensión en la narrativa de la vida individual en la historia colectiva, adoptándola como recapitulación del acontecer de las ciudades, enumerando no solo a las posicionadas en la frontera norte de México, que, siendo entes vivos y heterogéneos, sin desearlo, han asumido características deformadoras y fragmentarias sin precisar los porqués su deterioro.

Palabras clave: Apariencia, Masificación, historia colectiva, percepción. 


\section{INTRODUCCIÓN}

Antes de iniciar ésta investigación, una duda a provocado el desconcierto del autor y se ha preguntado: ¿Es por la realidad del entorno o naturaleza, más que por la apreciación de pertenencia que se sucede la vida y habitabilidad en las ciudades?

Es probable que para develar ésta realidad, como para advertir las deferencias sensibles del crecimiento de las ciudades, en una primera indagación se soslaye, cuales son los vestigios importantes $y$, que atender, más que entender el entorno, transfigura la situación en una variable que de forma diferente ha sido adoptada por cada habitante y suponiendo, a partir de intentar esclarecer las entrañas de su existencia socio-cultural, sea permisible alcanzar una respuesta donde podrá ser apropiable la opción de su desarrollo en lo unitario, a partir del cómo y de qué manera se ha incorporado al colectivo. Sin embargo, lo expresado, permite entrever que el entorno ha sido desatendido con extrema facilidad por los seres humanos, de forma tal que se ha convertido en una compleja situación al ignorar su deterioro a nivel global, propiciando de forma resiliente, su resarcimiento.

La atención asumida para continuar y esclarecer lo señalado, se propone tal como la formulan, Cimbranos, F., D.H. Montesinos y M. Bustelo (1999) al afirmar que; "conociendo la realidad hoy, se podrá alcanzar la alternativa de la realidad", en tanto en un sentido alterno de su comprensión, Castañeda, C. (1968), haciendo una clara referencia al análisis estructuralista de Levi-Strauss
(1978), lo alude como "los preliminares de ver y la tarea de ver".

Habría de comprender con las variables de lo anunciado, que se la hace referencia, que, al conseguir la realidad y disponer de la suficiente información, permita, por una parte a la investigación, enterarse de la extensión de las fortalezas existentes o tal vez también, del posible grado de deterioro y precisar la configuración de valores, identificados entre algunos de los intangibles, la identidad, la pertenencia, la capacidad de integración, y, siendo aún imprecisa su comprensión ontológica, se hacen ostensibles como características o circunstancias que la propician, cuando asintiendo imaginar, que la individualidad en el colectivo, debe reconocerse ser sociológica y que no solo porque forma parte de un determinado lugar, derivado el porqué y el cómo apropiarse; el estar y sentirse dentro de ella, se alcanza solo por la eventualidad de nacer, de adopción, causalidad o posible casualidad.

Pudiera ser esta afirmación, una oportunidad de deducir en términos relacionales, las discrepancias entre Bourdieu y Elías a la manera en como lo aborda Guerra, M. Enrique (2010) [...] "donde lo social y lo individual se aprecian como dos perspectivas de la realidad que no pueden separarse". Éste hecho, privilegia de forma puntual la aseveración e importancia que adquiere el comportamiento histórico generacional en lo individual y de cómo se verán impactados con la conservación o ampliación de más oportunidades vitales. Ya Christian Norberg-Shultz (1995), retomando el carácter espacial del habitar, desarrolló diversos estudios en torno a la

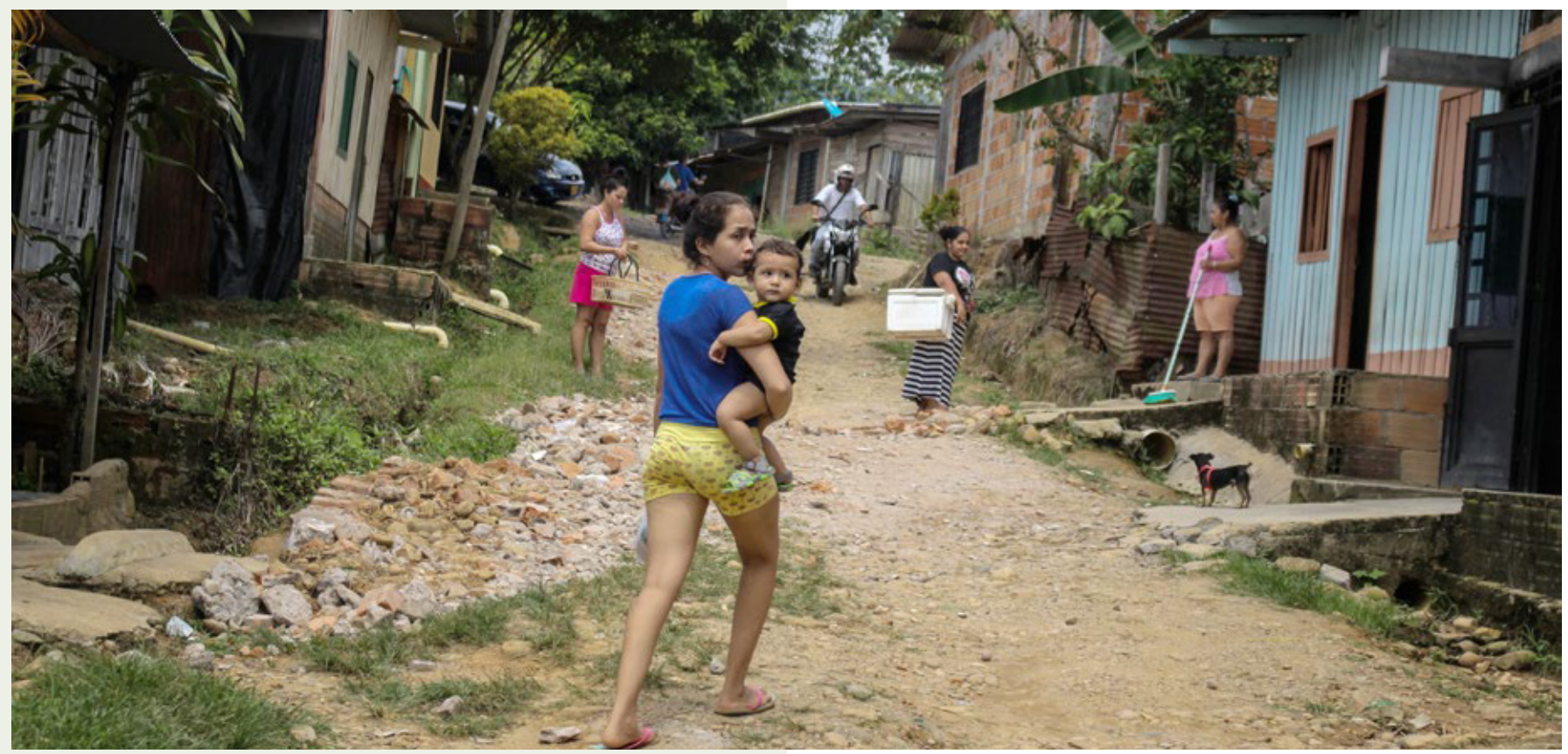


identidad y la pertenencia, el lugar, menciona lo que se ha venido advirtiendo, que la identidad está profundamente relacionada con los lugares y las cosas.

La visión de habitar el espacio y sus posiciones en la habitabilidad, setransfigura desdeel señalamientoquehace Bourdieu, al formularlo como concepto racional de hábitus y como una clara consecuencia a las formas de posición a través de sus disposiciones $y$, en éste caso particular, al referirse, que a cada parte de la ciudad, le corresponde una clase de hábitus resultado de las condicionantes sociales asociadas con su ocupación en el tiempo; en tanto, en lo individual, lo señala bajo dos actitudes; lo objetivo y lo subjetivo que caracterizan las estructuras sociales externas y se consideran las estructuras sociales internas, un todo reunido en el concepto de hábitus.

De alguna forma se ha de comprender que, desde éste apartado, se ha de construir la significación con la que se dado inicio. De algún modo y con ella, se desea percibir la realidad socio-cultural para, comprendiéndola, estar al tanto y entender la problemática surgida a partir de la visión de los actores insertos en los grupos y en las distintas sociedades para, conociéndola, -saber escucharlos-. Lo mencionado, lo reiteran los autores citados y al obtener la mayor información, se podrá estar en una posición de interpretarla. Al hacer la referencia a grupos se ha de atender lo expresado por Leví-Strauss (1978), "una realidad objetiva abordada desde fuera con independencia de la representación que los individuos tengan de ella y de la manera que cada sociedad trata de integrarse a todas en una totalidad ordenada"

Se hace deseable también señalar y tomar en cuenta como referente, el no perder de vista una variable que, independiente de lo pretendido alcanzar como objetivo, sea acaso ésta, una de las más sensibles percepciones advertidas dentro de las comunidades. $Y$ ya que ésta ha surgido desde la fenomenología, como un acto que está incidiendo en la vida acelerada de los habitantes, se hace referencia al estado de estatus de competencia, que, pareciendo implícita su interpretación a partir de lo financiero, se revela -sin ser un parámetro en la adopción de los elementos de confort de la habitabilidad-, se constituya en un referente que ha favorecido e influenciado la producción de espacios o viviendas placenteras, más no por sus características físicas de un diseño de una arquitectura pasiva, sino por el empleo y consumo de energía por medios maquinales que la hacen posible.

También es pertinente señalar que ésta condición, a pesar de la intensa penetración de la comercialización de los ofertantes, no ha alcanzado a ser reveladora dentro del esquema de las empresas dedicadas a la edificación de viviendas, producto tal vez, de otra variable constituida desde la elección de terrenos baratos, otrora ejidales y más alejados de la mancha urbana; escenario que menciona de forma puntual, Chávez Acosta O. (2018) en su artículo “Fragmentación urbana: relevancia de las preexistencias

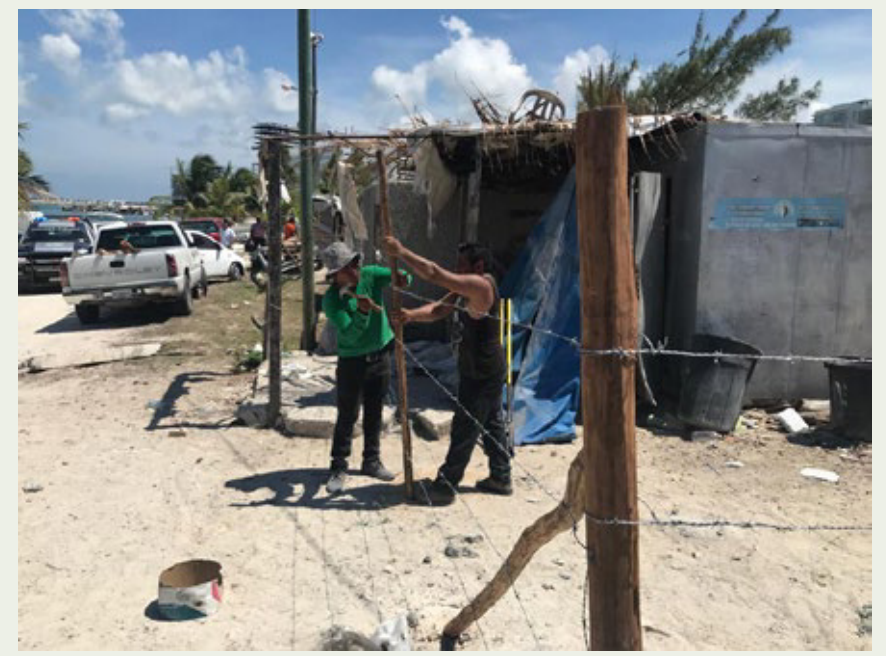

agrícolas" donde el crecimiento consecuencia de [...] "los cambios constitucionales reguladores de la tenencia de la tierra y el desarrollo de vivienda, como factor de base contribuyeron al establecimiento de las condiciones espaciales y de paisaje urbano de la ciudad actual". Por lo que apuntar que lo alcanzado a partir de lo mencionado, solo ha logrado fragmentar más la ciudad al encapsularla con nuevos asentamientos cual si fueran cotos del poder de la economía, instaurando una realidad incierta y potenciadora de una mayor segmentación y desarticulación de los grupos sociales y colectividades, ya que, al desarrollar núcleos urbanos más alejados del centro fundacional, su propuesta aparece como una visión del crecimiento no planeado en el desarrollo de las ciudades.

Tal como lo señala acertadamente Chávez-Acosta, "[...] el crecimiento de la ciudad es normado y regulado, de manera general, por el ayuntamiento; pero los desarrolladores privados lo materializan en el territorio, siendo los verdaderos creadores y constructores de la ciudad". Si bien el caso citado en específico, corresponde a la ciudad de Chihuahua, se puede afirmar, que este es un modelo que se replica en muchas de las ciudades del País y posiblemente, en algunas ciudades de Latinoamérica.

Imaginar ésta situación como parte de la reflexión inicialmente externada e interpretar las formas en las que la habitabilidad en lo contemporáneo ha evolucionado en la mayoría de las ciudades del continente y precisar que inició como un efecto de las políticas económicas adoptadas en la década de los años ochenta del pasado siglo, permitiendo la propagación de empresas inmobiliarias y crear"paquetes de vivienda amurallada", e implementando modelos masivos de vivienda, fragmentaron las costumbres al poner en duda la aceptación y formas de diseñar los espacios que debiendo ser sensiblemente humanos, se alejaron de garantizar y justificar su calidad como lo es. el hecho de ocupar un lugar para vivir o morar en una casa o espacio con confort y dignidad.

La masificación, identificada como una parte del proceso de la ciudad en lo contemporáneo, se ha ilustrado 
desde el inicio del texto, juega un papel trascendente en la transformación de la mayoría de las ciudades Latinoamericanas en donde la narrativa expresada por Ricoeur (1997), hace ver su comprensión en la historia colectiva de la vida individual, para adoptarla como recapitulación del acontecer de las ciudades, asumiendo características complejas, deformadoras y fragmentarias, que con frecuencia pretextan los porqués del deterioro del hábitat.

Hacer mención de las causales de la apariencia adoptadas en la vivienda contemporánea, particularmente la de carácter masivo, la referencia mencionada de Lambert (1764) debiera acotar y transformarse viendo los efectos que su proliferación ha producido en el ambiente natural, en el comportamiento individual y el colectivo, afectando la vida en las comunidades y sociedad, el caso es que al suceder lo aparente, se renuncia a la propia identidad.

Deliberadamente se asume el propósito de exponer las facetas inacabadas de lo enunciado y profundizar en los conocimientos asimilados de la edificación vernácula, por considerar que su importancia en la vida, y espacios, se muestran como pilares y tema de aceptación en el quehacer y recuento de pertenencia y herencia ancestral de la identidad, al enunciar y reconocer a los pueblos y naciones primigenias, al permitir develar los silencios de las culturas mesoamericanas asentadas anteriores a la ocupación hispana en los territorios de pertenencia para después, constituirse mestizas.

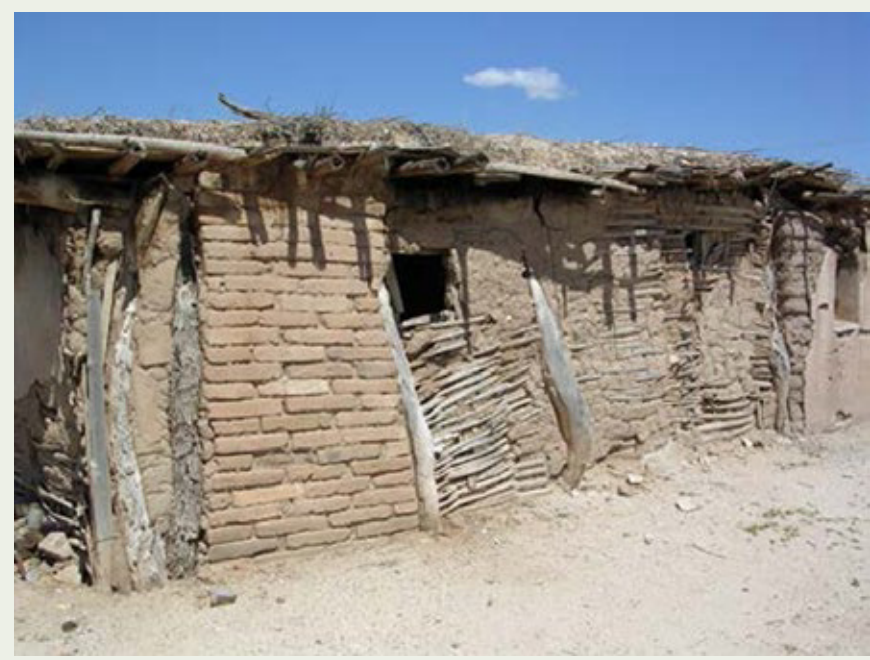

Figura 1.- Vivienda mestiza en el poblado mayo de Choacalle, Sonora.

Prop. De Carlos V. Tostado C. 2004.

Ya que siendo ésta parte de los testimonios de lo construido y legado de la heredad, la diversidad de formas de la habitabilidad bordadas por el clima, la naturaleza, así como de lo efímero e intangible de las significaciones, en muchas ocasiones como una respuesta del lugar, se debe precisar que no solo las posicionada en el nororiente del país, permitirán hacer un inventario de lo edificado y examinar las diferencias de lo idealizado por sus habitantes, sociedades y grupos, quienes mostrando mesura en los estilos, plástica y poética de sus espacios como consecuencia de las formas, geometría y materiales adoptados en sus edificaciones, parecieran ejercer una sensación de fascinación a partir del empirismo nativo que, al apropiarse de su entorno, argumentando y advirtiendo lo sustentable y lo expresado hasta hoy, el tema de lo resiliente derivado de las afectaciones y deterioro de y a la naturaleza, haciendo vigente y presencial su rescate.

Sustentable y resiliente, son en este tiempo, antónimos en la defensa al medio ambiente, que, aunque el primero pretende hacer que las cosas se sucedan de forma preventiva con el afán de heredar las bondades del planeta, la segunda intenta recuperar lo dañado por la inexcusable tarea del ser humano que, en pos del progreso, ha destrozado los rizomas de su existencia.

En tanto, lo identitario, develado como patrimonio intangible de la plural semejanza nacional, se ha constituido, por una parte, en parte del resultado de los conocimiento, tanto de las condiciones del entorno, como de las características y propiedades de los materiales empleados $y$, al igual que las formas del hacer uso de la tierra aplicada en calidades múltiples y asumiendo el conocimiento occidental del hacer del adobe de tierra cruda, transformándolo en prototipos y tipificado mestizo, lo entremezcla con frecuencia, con las formas de hacer de sus antepasados como lo fue el tapial, el bahareque o chiname y el contemporáneo, BTC o adobe de tierra-cemento así como el ladrillo o tabique recocido, convertidos todos ellos, en un valioso tema de análisis que lo hace imaginarlo un objeto de interés por su aplicación, particularmente, para lograr espacios eficientes, agradables y ecológicos.

\section{Referencias desde la práctica.}

No obstante que los diseños en la modernidad se han distanciado de su uso por ser considerado un material de los pobres y denostado por su carácter indígena, su uso debe considerarse al adaptarlo al presente, un valioso recurso para atender la demanda de un amplio segmento de la población que carece de un espacio habitable con dignidad y calidad.

Es deseo del autor en éste artículo, a partir de exponer una semblanza en donde se destaque la importancia de la arquitectura vernácula, en éste caso de estudio de la vivienda de los mayoam, particularmente de las formas con la que los antecesores indígenas mayo, construyeron con idoneidad sus lugares $y_{1}$-sin menoscabo de su pertenencia-, presupone que aún con la cierta rusticidad de los procesos de formación, su identidad se considera consolidada con sus propios valores para transferir sus tipologías, materiales y tecnologías de forma consciente, de forma que se presenta como una forma congruente de adaptación al medio ambiente ya que han logrado obtener 


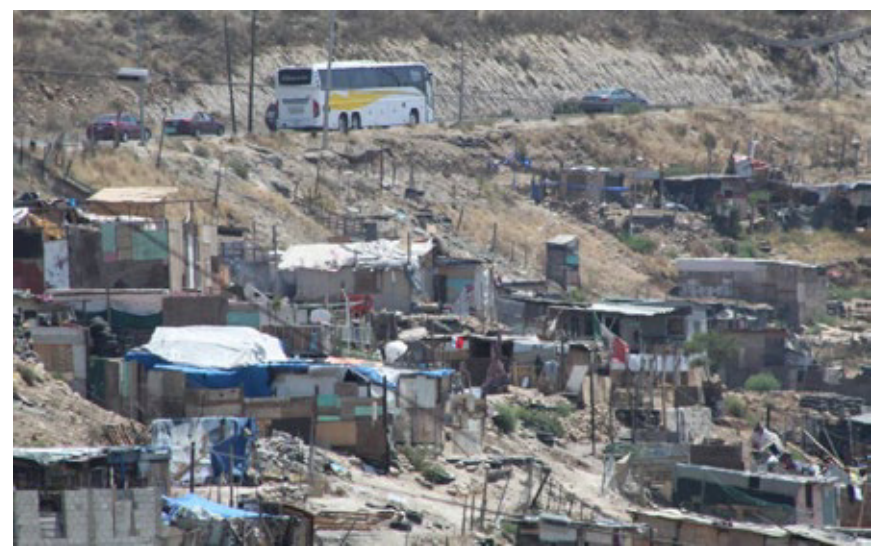

como recompensa, la preservación, cuidado y originalidad de su hábitat y sus paisajes.

$\mathrm{Si}$ bien es menester hacer una referencia al espacio como centro de la habitabilidad y esta conlleva a plantear y reflexionar sus significaciones. Mientras que algunos autores la describen contenida dentro de límites, la tarea de precisarla, deberá ser a partir de ese "algo" que evidentemente considera sus contenidos intangibles que alienten la búsqueda de respuestas a su significación, ya que en su ocupación, no solo se considera el precisar un lugar, sino debiera ser algo que la identifique dentro de límites que finalmente no son ese algo y desde donde "algo" se termina, sino como se reconociera en la cultura griega, es el límite de aquello desde donde comienza su ser. Espacio en esencia, espacio creado, es, lo que tiene cabida en su límite. Martin Heidegger (1951) en su ensayo; Construcción, Habitación, pensamiento, afirma que "Los espacios y con ellos el espacio, ya está siempre creado en la estadía de los mortales. Los espacios se abren cuando se les da cabida en el habitar del hombre."

De lo descrito, se rompe de nuevo el silencio para argumentar el porqué del quebrantamiento del comportamiento humano con sus raíces, entonces la heredad de la arquitectura, siendo un proceso transformador de la realidad y resultado de una metodología culta y científica, es en sí misma, es una actividad intelectual.

Al proceso en el avance de la exploración, le quedan claras dos inquietudes.

1a. ¿Porqué si lo que se desea es el espacio; es decir, lo contenido entre límites para habitar, ¿cuál es la razón para objetar el empleo de materiales vernáculos?

2a. ¿Cuál sería la razón del éxito de los conjuntos habitacionales amurallados si lo que no tienen es el espacio para habitarlo con dignidad?

De la misma manera en que la verdad, "como conformidad de las cosas consigo mismas o de lo que se dice con lo que se siente o piensa" según se enuncia en lo universal, se transforme en un hecho y para antes de enfrentarla al ejercicio de proyectar, se considere ineludible efectuar un proceso recolector de la realidad concreta y a través de ella, obtener información que sea para el diseñador, un instrumento eficaz, no solo a consecuencia de sus antecedentes históricos cuando se devela la realidad desde su identidad y presencia de pueblos y Naciones entones; ¿que se requiere para alcanzar la significación de la premisa del rescate de los elementos de la vivienda en lo vernáculo?

Se ha de consideraren el ámbito del espacio temporal las variaciones de este tipo de construcción, en que las significaciones socio-culturales de sus estructuras, al adoptar y/o aceptar los individuos, grupos y sectores sociales los diferentes modelos de vida, para con ello reflexionar que en el propósito mismo de estudio, está contenido implícitamente en el empleo de tecnologías constructivas tradicionales o en la modernidad de los materiales, la configuración del posicionamiento y del entorno derivado de sus dogmas, ya sean estatus social, académicos, religiosos y cósmicos, se advierte que bajo ésta premisa, se encuentra la posibilidad de rescatar, desde la incierto del valor, el equilibrio y hasta la protección del entorno, a una naturaleza que no solo debe ser representada bajo el esquema de "antiguo, vernáculo o tradicional" y menos, como lo han expresado de forma denostante, un signo negativo de pobreza, deseando conferirle una diferente lectura a la relación -hombre y medio ambienteya que se ha de considerar, continúa afectando a todos los niveles de vida, alcanzando al mismo hombre que se pierde destruyendo los ecosistemas, incrementando la contaminación, la violencia y la destrucción.

\section{Estructura de trabajo.}

Idealizar una forma de presentación que conduzca con acierto y lograr una visión de lo que se pretende exponer en pocas frases, deja ver en la inexperiencia del autor, un reto derivado de la gran cantidad de variables que deberán ser acotadas en virtud de lo limitado del espacio a disponer en su redacción; sin embargo, se intentará puntualizar a grandes rasgos, la importancia que posee el tema y la impresionante forma en la que se les está arrebatando de las manos, sin darse cuenta las nuevas generaciones, su herencia.

Primer apartado. Conociendo la realidad hoy. -Preliminares de ver-.

En el estudio científico de las etnias, la etnología, se ocupa de la estructura lingüística, económica y social de cada una de ellas en cualquier parte del mundo. De ella se valora la intensidad que ejercen sus lazos en una civilización que las debiera caracterizar permanentes en su evolución. Sin embargo, al meditar que se tiene un panorama incierto de dimensionar y que se teje de forma compleja a partir de advertir la condición de un mestizaje que habría que estratificar a la manera como lo hace el citado autor Castañeda $C$, dilucidando los porqués de las diferencias culturales y apreciación de sus costumbres, símbolos y significados de un lugar y forma de ver la 
vida, estando insertas dentro de los componentes de los estudios de campo, se advierten forma de aceptación y/o rechazo en el uso de siluetas precisas en suficiencia a sus necesidades y la implementación de su diseño, con materiales pertenecientes a su entorno.

Segundo Apartado. Alcanzar la alternativa de la realidad. -La tarea de ver-.

Inherente: adjetivo. Que por su naturaleza esta de tal manera unido a una cosa que no se puede separar.

No se está en condición de afirmar, que es lo inherente al conocimiento y sentir de cuál es la percepción que se tiene de la ciudad y que es lo que envuelve a las generaciones, agrupaciones y personas en la ciudad, como tampoco se puede atestiguar que se podrá elaborar un plan para transformarla en un tiempo mediático. Sin embargo, lo que se posible alcanzar como conocimiento holístico, será de interés de todos para, una vez advertidas las coincidencias, los avances que se alcancen en diferentes senderos, serán trascendentes.

\section{Se diría que es conveniente que la condición de} inaplicabilidad de los estados de la realidad no ordinaria como lo que plantea Castañeda, quien introduce el concepto de -nuevas unidades de significado-, preconcebidas como un conglomerado básico de datos sensoriales y sus interpretaciones sobre las cuales construir un significado más complejo. Sería tanto como enumerar y llamar a los espacios por un nombre que se requiere,

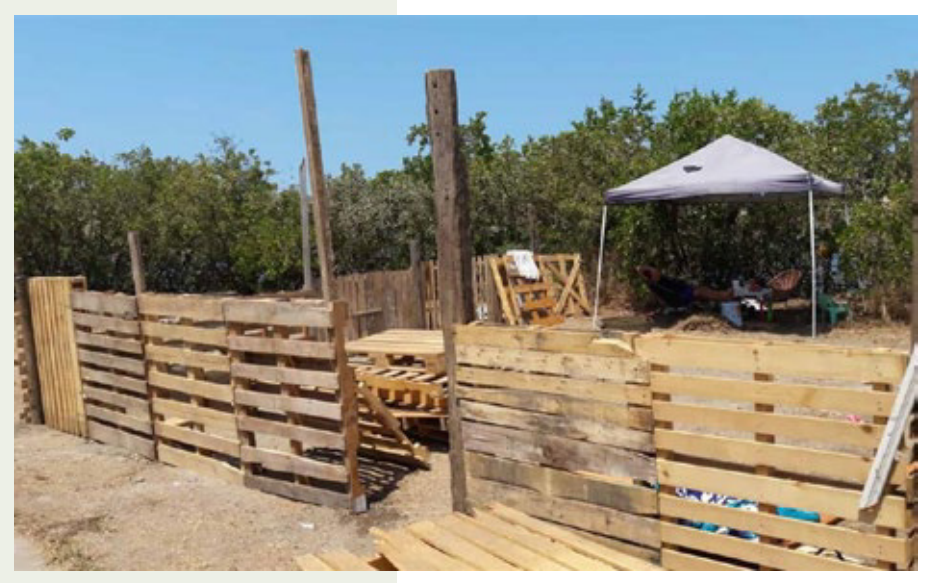

necesario de las viviendas, para hacerlo todo para sentir la admiración y parecer importantes, a base de equipamiento y costo de inversión.

En el Tercer y conclusivo apartado, la metodología adoptada en la revisión de las topologías, tipos y estructura de los espacios, al igual que la función, se ve con una adecuada selección de tecnologías prevalecientes y con una visión holística, se demostrara que los resultados de los estudios de caso abordado, en mediación de la corta distancia prevaleciente de los asentamientos estudiados, permitió obtener la valoración de los componentes más importantes a través del enfoque metodológico propuesto. Se reorientará el trabajo investigativo en reformular desde un ejercicio epistemológico para que se fundamenten los valores socio-culturales que, expuestos de forma detallada del devenir histórico de la etnia, logrando describir las características más relevantes de su territorio, los aspectos demográficos y los valores que han potenciado su identidad, cultura y lengua. En ellos, se retoman, tanto las Anastilosis como las analogías con sus referentes correspondientes, para presentar el testimonial que permita identificar la realidad, problemas y oportunidades de la vivienda mayo, que facilite la oportunidad para ser discutidas en un marco que consideramos, rebasa el ámbito acapara atender e identificar la vida de los individuos, de una pareja, de una familia o de un grupo numeroso de familias y/o personas en lo cotidiano, tanto como exponer un sistema preciso de interpretaciones sensibles con las cuales, cualquier interesado, puede lograr coincidencias y realizar cita el autor, "aclamaciones, supuestos, predicciones, etc., sobre todas las situaciones pertinentes a su actividad".

No se puede dudar que, para adoptar una interpretación coincidente y sensible, debe preexistir un proceso para interpretar los datos percibidos de las acciones individuales y sociales. Las apariencias, que se han adoptado, se asumen no por lo que significan sino para parecerse a otros en lo lejano o extranjero, sin suponer, se tenga alguna responsabilidad al adoptarlas asumiendo pensamientos con certezas emotivas, las evidencias de afectación a la naturaleza se muestran simuladas y maquilladas.

De lo aprendido, pareciera que no se tuvieran rastros de haberlos recibido. Más bien, aprendemos a pensar diferente y se entrena a los hijos para que lo adviertan de la misma forma, aunque no se alcance el sentido de confort démico y en un intento de ser concluyente, se describirán los componentes y elementos tradicionales, no solo de la construcción de sus viviendas, sino exponiendo con pertinencia que la vivienda vernácula es, y continúa siendo, patrimonio y herencia cultural donde sus construcciones han sido diseñadas con un lenguaje claro y adaptado al medio ambiente, adoptándolo con contenidos de símbolos propios.

\section{Significaciones y características epistemológicas,}

Para identificar los límites y establecer un contiguo entre la arquitectura vernácula y la arquitectura culta académica, habría de vencer el obstáculo epistemológico para, definiendo la arquitectura vernácula, se codifiquen los patrones establecidos que se escapan por no ser académica. Equipararla, conlleva a la aceptación de formas y modelos en la que se da por hecho, una misma estructura de identidades a través del tiempo. Sin embargo, no se han sentado las bases de los límites del vernaculismo en la que se hace valioso y relevante, la recopilación de los diferentes pensamientos y donde la propuesta de su valor y concepto, la respalde y consolide. Si entendemos que la arquitectura es 


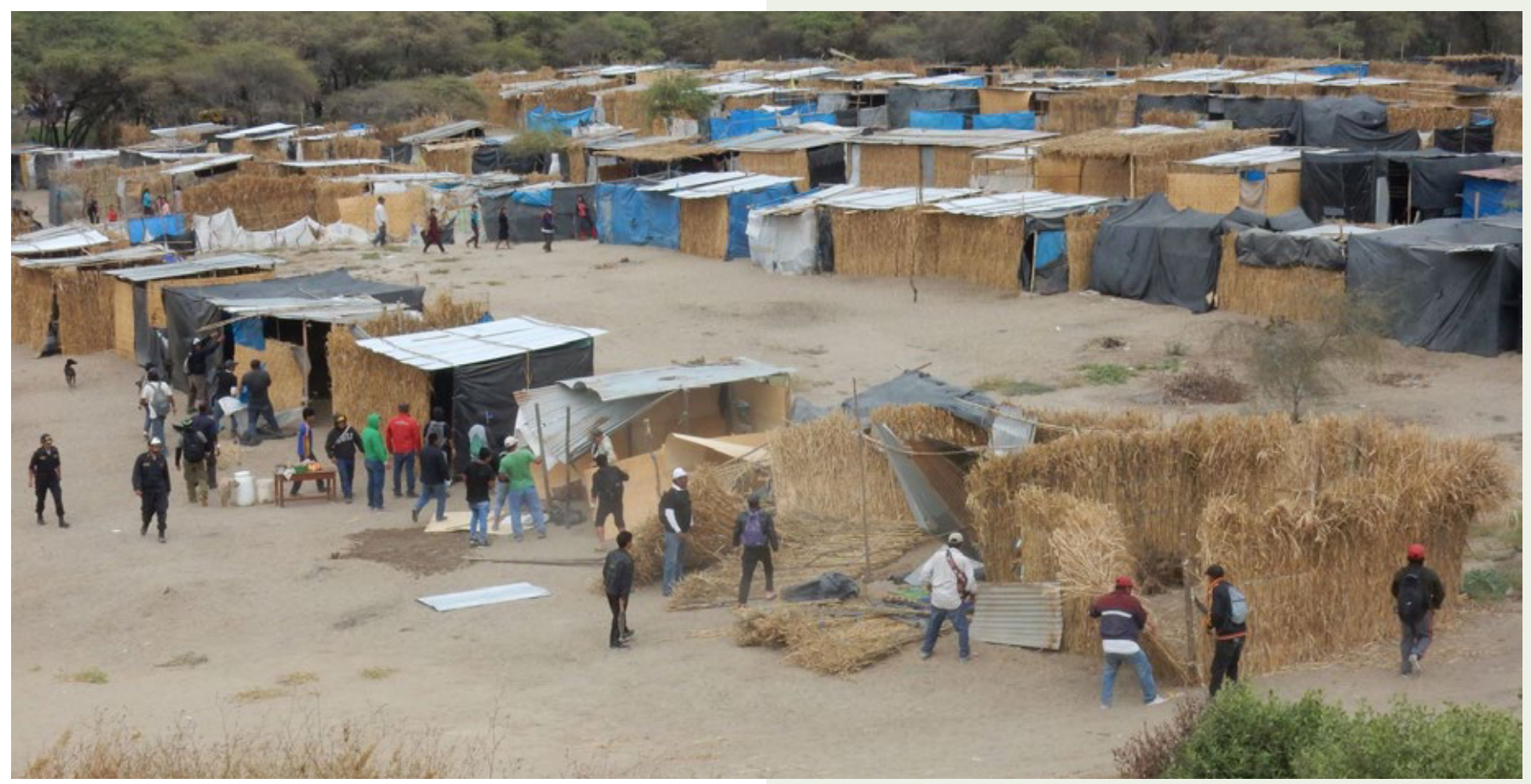

la sumatoria del trabajo de muchos individuos; entonces el resultado será a partir de diferentes modelos de vida de trabajo colectivo y social con innumerables contribuciones impersonales e inconscientes; además, sería la expresión de una cultura, de una época y de una tradición constructiva; arquitectura de formas que se hicieron convencionales obedeciendo a reglas no escritas.

Cuando se presta atención a la información de que los elementos de la vivienda vernácula han sido abandonados o caído en desuso por circunstancias, eventualidad o por las cambiantes formas de vida a consecuencia de la acción del proceso de modernización por la globalización, los conceptos con los que fueron aprehendidos, deberían ser exteriorizados por el esfuerzo de su logro y no solamente a consecuencia de un discurso impresionable, aún sin saber con certeza, si al hacerlo, preexistieran las referencias a los valores intangibles como la identidad, la territorialidad o la pertenencia material, por lo que ésta tarea debiera trascender a la ocurrencia cuando advertida su claridad, se viese como una forma privativa de que no es útil a los demás, naciendo la invitación para reflexionar en torno a la armonía y al grato equilibrio sistémico de la naturaleza, cuando debiendo valorar la noción de integridad y el imaginario de una cultura, se demanda alcanzar determinados atributos cualitativos que implícitamente reclaman de una organización social integrada al ambiente y una manera en la que el impacto producido después de la propuesta no resulte en la destrucción del ambiente sino que, respetándolo, lo reconstruya.

Resalta y deja al descubierto esta postura, el que hayan sido los grandes problemas humanos propios al aislamiento y creados al inter-actuar la gente con el ambiente natural y no solo la negligencia colectiva, la que ha arrastrado a las sociedades a una catástrofe ecológica; lamentablemente sin atisbos de una nueva prerrogativa.

En tanto se pone énfasis en el nivel local, se advierte que a pesar de todos los controles establecidos en las diferentes comunidades "Yoremes", como a sí mismos se llaman, también se ha venido perturbando su sentido de identidad a consecuencia de los cambios culturales, producto de su imbricación con una sociedad, donde la continua asimilación se diferencia con el modelo mestizo, usurpando a la sociedad indígena, al romper los límites de los espacios públicos, su economía, en lo político y en lo social, de la misma manera afectando al espacio privado, donde se gestan y reproducen las identidades de los grupos resistentes a la influencia externa. La ventaja o diferencia de éste esquema significa, que la articulación entre la sociedad humana y su entorno, debiendo ser analizada a partir de su dimensión ambiental, -como parte del fenómeno cultural-, se ha constituido inserta en las disciplinas ambientales para seguir siendo un instrumento "apropiado" del estudio-nexo entre la cultura y ambiente, sociedad y entorno.

La condición de "apropiado" deriva de su historia epistemológica como ciencia de la cultura. Los estudios de las etnias prístinas del mundo iniciarán, despojando del contacto con los grupos humanos cuya relación con el ambiente era esencialmente distinta a la del resto de las sociedades occidentales y occidentalizadas y deseando apropiarnos, en la medida de las posibilidades para situar en congruencia y llevar esta aspiración a supuestos concretos, alcanzar la profundidad del tema.

El análisis intentará posicionar una oferta específica fundamentada en un ejercicio a partir del diseño 


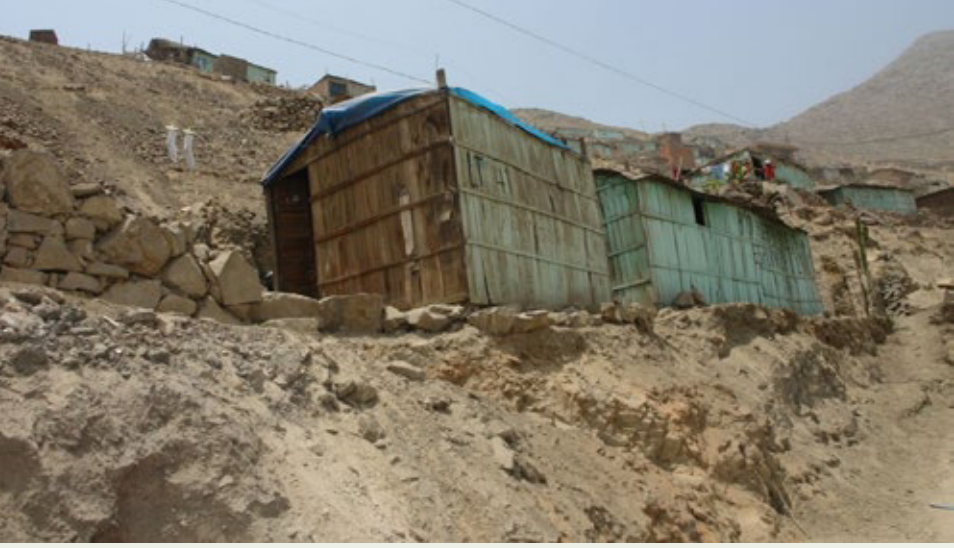

arquitectónico de la vivienda mayo develada desde una clasificación recogida e interpretada de los elementos posicionados en cuatro comunidades y se precisan los casos de estudio por cuya cercanía a su entorno natural, se dio la elección de los sitios específicos, saber y dar cuenta de los símbolos y significados de la construcción tradicional de la vivienda mayoam, para al clasificarla, se cualifiquen y registren los elementos constructivos que distinguen su conformación, calidad e identidad a partir de su sencillez y respeto a los modelos y materiales usados dentro de su naturaleza, procediendo con recatado atrevimiento que, al apropiarse plenamente de su espacio físico y medio ambiente desde tiempos ancestrales, muestran hasta hoy con su presencia, una importante imagen de carácter contemporáneo, tan actual y tan importante como en los mejores tiempos de su acontecer histórico.

\section{El emplazamiento urbano.}

Es relevante indicar, que el espacio público arquitectónico en época mesoamericana, se constituía como el centro del entorno urbano y como el componente más importante del espacio abierto de encuentro, entorno a las deidades de su heredad que al tiempo fueron suplidas en el acontecer histórico de la conquista, con la presencia y símbolo de la cruz hasta mimetizada, entrelazar el sincretismo de sus creencias.

El hecho de que la cultura indígena mayo, no posea un referente con posición en lo que concierne a sus valores vernaculares, desafortunadamente les ha privado de la identificación de sus incipientes fortalezas y por ese solo hecho, se vuelve difícil involucrarse en una investigación que carece de referentes, dando muestra del poco interés que se tiene de las raíces étnicas de la región. Por ello, se debe destacar, que aún existen los testigos y testimonio de los centros ceremoniales prehispánicos en nuestro tiempo y muestra de ello, es la Piedra de la Cruz localizada en Teachive, Sonora, que en su emplazamiento se guarda una cuidadosa distancia a las edificaciones colindantes marcando senderos trazados con piedras de canto rodado que alineadas, definen los lugares de comunicación del alrededor para tener el andar que conducirá al encuentro del punto central del lugar ceremonial prístino que después de la presencia hispana, es alterada con la intromisión del símbolo de la cruz (figura 2 y 3 ) realidad que se conserva en sincronía a la distancia prefigurada históricamente principalmente, al frente de los templos católicos.

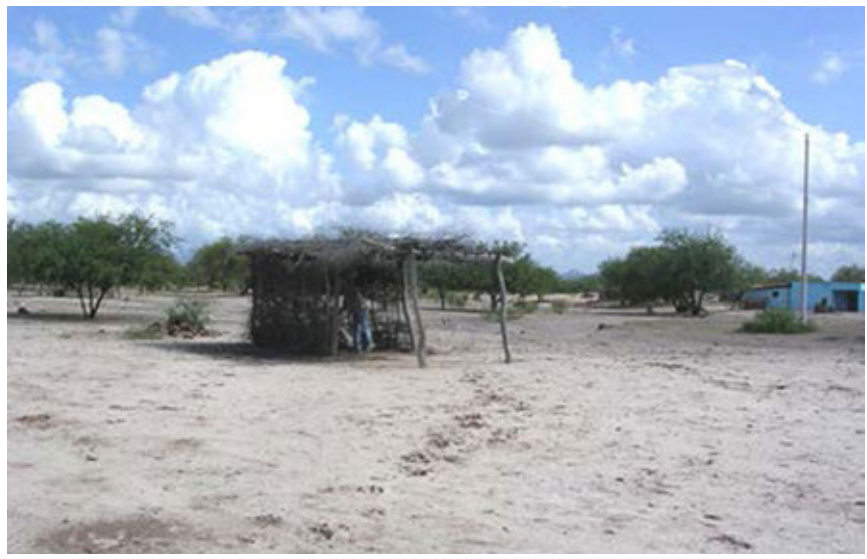

Fíg.2.- Emplazamiento de la Cruz de la Piedra, espacio abierto dedicado al culto ancestral Mayoam, localizado en Teachive, Sonora.

Prop. De Carlos V. Tostado C. 2004.

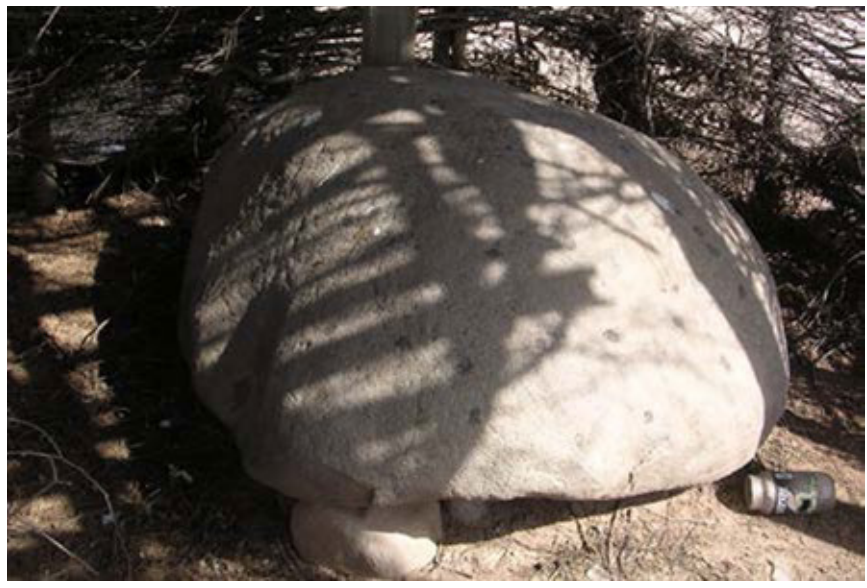

Fig. 3.- La Piedra de la Cruz y detalle de grafías, localizada en Teachive, Sonora. Petroglifos y simbolismos.

Prop. De Carlos V. Tostado C. 2004.

\section{Proceso y revisión de las topologías, tipo y estructura de los espacios.}

Ya que la selección de modelos tiene inicialmente un carácter aleatorio se debe mencionar que las primeras experiencias realizadas se hicieron en la comunidad Mayo del Siviral dentro de la ciudad de Navojoa, Sonora, sitio que conserva algunas construcciones que datan a finales del siglo XVIII como también se registran procesos de obra 
tradicional en la elaboración de proyectos comunitarios, para después continuar la investigación a la población de Masiaca y dada la cercanía de las poblaciones del Choacalle y Teachive, se incorporaron al trabajo.

Para referir el estudio a la imagen, tipo o forma, se hace sustentada en base a la referencia a la idea de tipo a la que Carlos Martí Arís (1993), propone como estrategia que sea el concepto usado como fundamento epistemológico que permitirá que el enunciado lógico se exponga con un carácter exploratorio permitiendo fijar la atención para concentrarla en los rasgos esenciales del problema analizado y sus emplazamientos, que serán parte inseparable de las vivencias, -particularmente de las registradas en los casos de estudio, el proceso metodológico de la propuesta se basa en el diseño y estructura de la distribución de desplante arquitectónico, así como de los elementos y partes que la integran, alcanzando a percibir desde su análisis, que los criterios se basaron en la percepción del dimensionamiento de los espacios, disposición de volúmenes, vacíos y entorno.

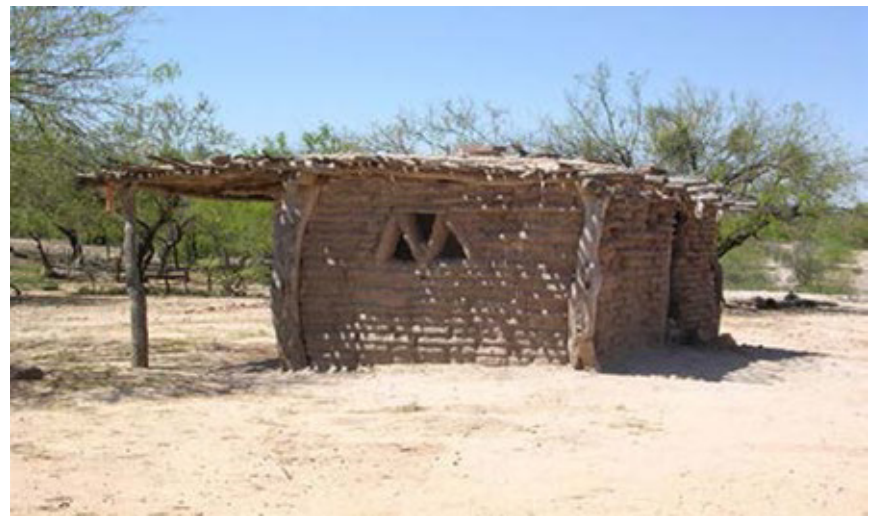

Fig. 4.- Estructura de horcón, viga de madera (tronco), morrillos y cama de corazón de pitahaya, para recibir terrado.(construcción en Masiaca, Sonora .

Prop. De Carlos V. Tostado C. 2004.

No es difícil considerar, y es posible, que dentro del simbolismo y significados del uso de los materiales apropiables y del empirismo de la mano de obra que, en el estudio de la arquitectura vernácula regional, se advierta, que una vez que la construcción pragmática satisfacía al hombre, ya no había cambios substanciales, por lo que los llevó a repetir la imagen grabada en su mente. La imagen retenida, trasmitida y repetida en una nueva construcción, sin ser casual, es uno de los elementos que ha generado que la arquitectura vernácula, bordándose en arreglos a los modelos transmitidos por generaciones y que varían según los materiales de cada región, al igual que las necesidades específicas de cada habitante.

Pareciera ser bajo este discurso, una bizarra lectura en lo contemporáneo mostrada a partir de la aparición de los conjuntos habitacionales en los que los tres o cuatro modelos de fachadas y un par de alternativas de distribución de los espacios interiores, hacían que la repetición sin ser originada en lo vernáculo, cubriera una imagen retrasmitida y repetida de carácter mediterráneo, asimilada mercantilizada como resultado de la moda a consecuencia del neoliberalismo.

\section{Emplazamiento y tipología de las viviendas de la etnia mayo.}

En la realización y registro de los resultados de los trabajos iniciados en orden de los lugares visitados así como por la relevancia de distribución de las formas arquitectónicas, función orgánica, componentes estructurales, partes y elementos constructivos que la integran, se develan el tipo y/o de las tipologías que le son propias para concluir finalmente, con un ejercicio epistemológico en el que sus valores socio-culturales se fundamentan y se exponen de forma detallada en el devenir histórico de la etnia, en el intento de describir las características más relevantes, tanto de su territorio, como los aspectos demográficos y los valores que han potenciado su identidad, cultura y lengua.

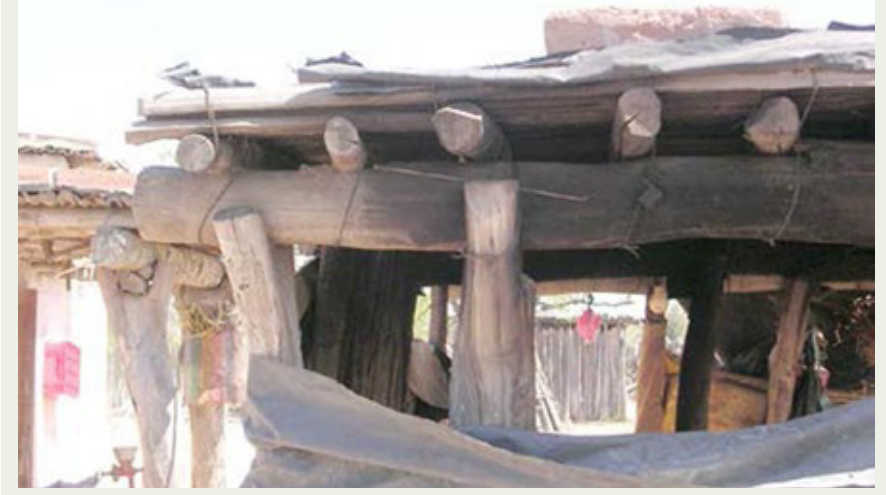

Figura 5.- Vivienda mestiza en Choacalle, Sonora, mostrando la estructura de horcones, vigas y morrillos, cubiertos sus muros con adobe y ramada cubierta de tierra.

Prop. De Carlos V. Tostado C. 2004.

No incumben, en un supuesto, los aspectos fisonómicos de la arquitectura al hablar de tipo desde el momento en que se reconoce, -entre ciertos objetos arquitectónicos-, la existencia de similitudes estructurales, al margen de las diferencias en el nivel más aparente o epitelial. Se trata de identidad arquitectónica que se asume en variantes formales percibidas a través de ejemplos diferentes, sin denostar que la idea de tipo, presuponga una actitud indiferente con respecto al problema del estilo, al vincular la arquitectura a la historia frente a un aspecto del desarrollo de la cultura material, a recursos o a una técnica constructiva determinada, ya que al encontrar referencias a determinados tipos arquitectónicos, incorporados a una dimensión cronológica, simultáneamente representa la arquitectura de un tiempo y un lugar precisos. 


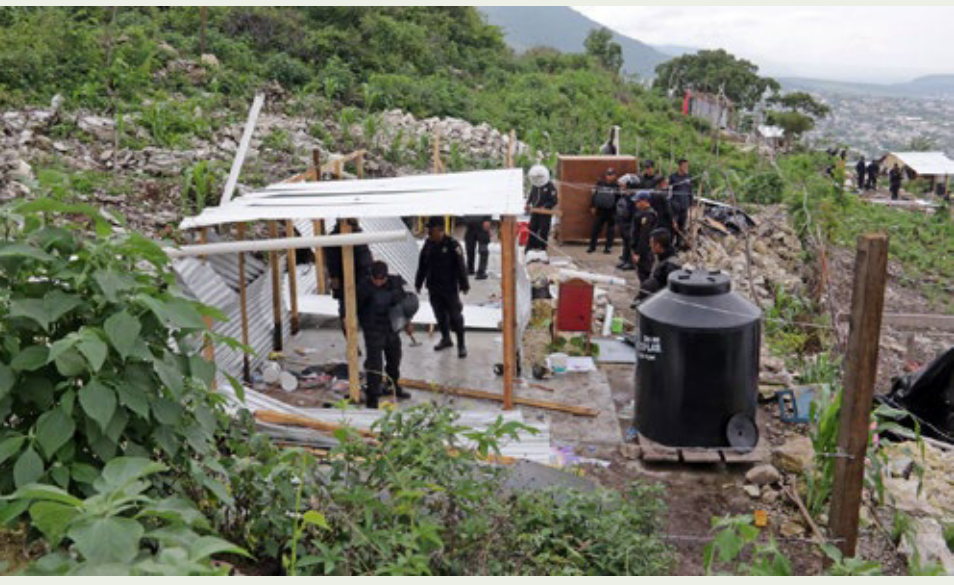

El modelo básico reconocido de las construcciones de las etnias yaqui, mayo y guarijíos, es la "ramada" construida a base de horcones y morrillos de mezquite cubierta de ramas para lograr sombra y desde ella, se generan algunas de las propuestas como las mostradas en la figura 7, en la que se aprecia la intervención del sistema constructivo mixto y mestizo derivado de la intervención horcones, muros de adobe, bahareque y ladrillo con una ramada con sobre techo acabado de tierra. Los emplazamientos de las viviendas elegidas como parte del estudio de caso en las diferentes comunidades mayo, se registran a partir de su geometría, emplazamiento y orientación dentro del predio que, durante el estudio de campo en las cuatro poblaciones, el intento en un intento de identificar el esquema de posicionamiento no se logró advertir un grado de exactitud en lo referente a superficie de posesión y propiedad, siendo interesante señalar la escasa palizada y el mínimo uso de alambre con púas para determinar la propiedad y defender la seguridad en los límites del predio, así como también la ausencia de líneas de alimentación de energía eléctrica y de servicios de agua potable, las calles sin banquetas y de tierra.

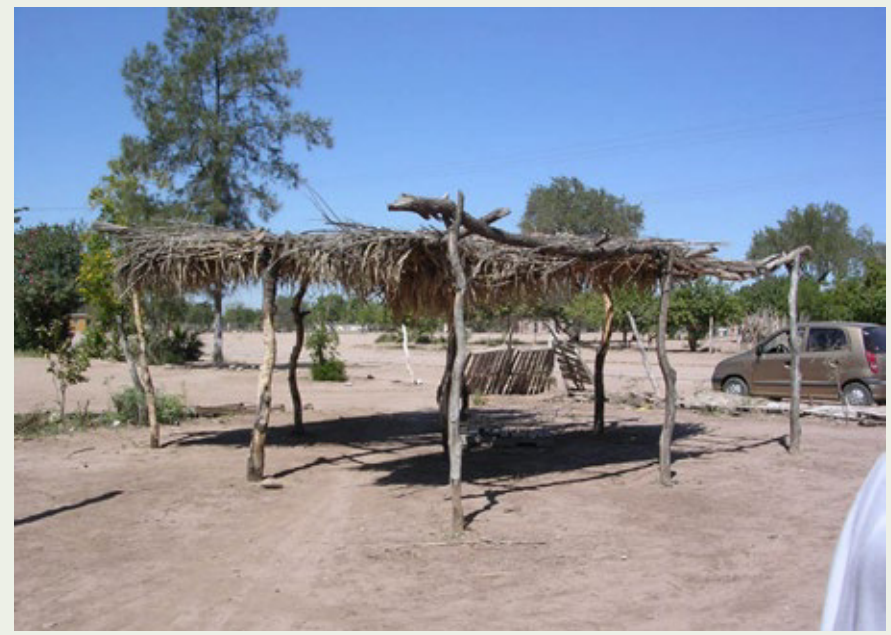

Figura 6.- Ramada del centro comunitario en la población del Siviral, Sonora.

Propiedad de Carlos V. Tostado C. 2004
La casa mayo se construye con diversos materiales en ocasiones combinados a pesar de sus diferencias de origen. Un tipo de casa, es hecha de bahareque, con carrizo o corazón de pitahaya o sahuaro enjarrado de adobe. Los postes de mezquite están fijos y en ocasiones, el techo es una estructura de madera y carrizo con emplastes de tierra y en otras utilizan plástico industrial para impermeabilizarla.
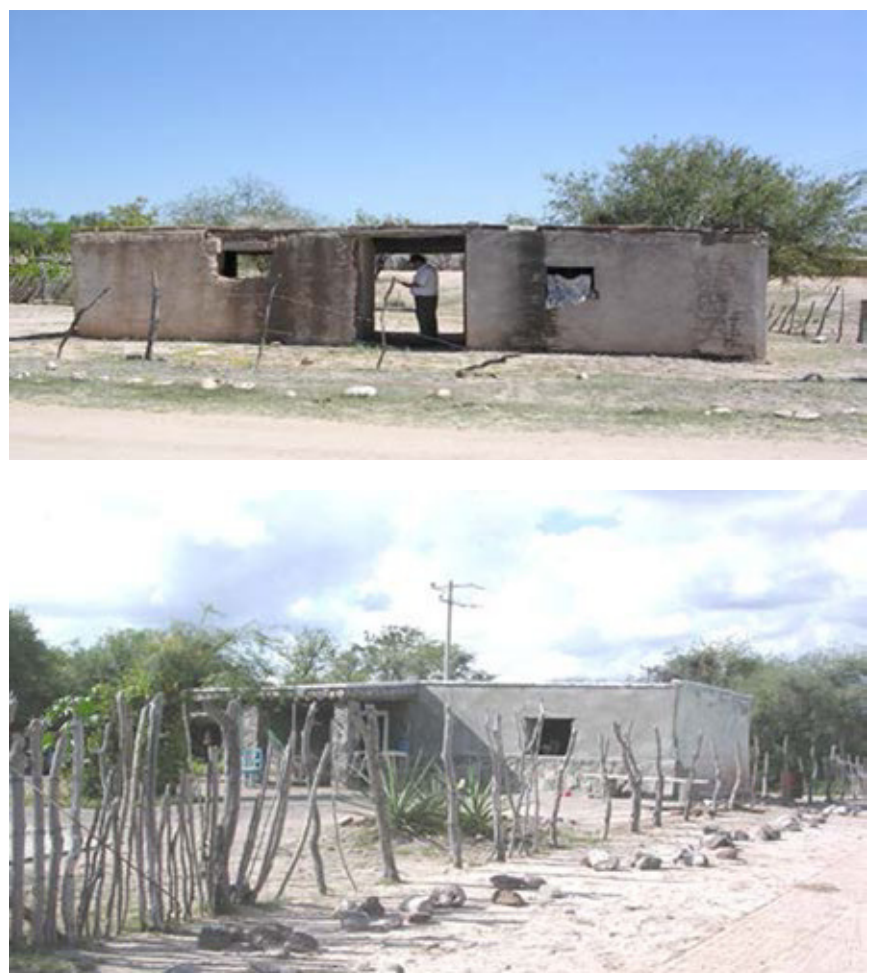

Figuras 7y 8.- La vivienda mestiza con muros de adobe y terrado en techumbre, es emplazada, muchas veces, a corta distancia de la calle y con escasa vegetación. En la construcción se observa una ventana de dimensiones mínimas y orientación hacia el poniente, en tanto el ingreso principal se posiciona hacia el sur para aprovechar los vientos dominantes en verano.

Propiedad de Carlos V. Tostado C. 2004

El uso del adobe con aplanados, enjarre y encalado, se hace para evitar que la destruya el salitre, muy común en algunas comunidades. Normalmente, todas las casas tienen una gran ramada hecha con postes de mezquite y cubierta con carrizo, tule o palma, según la región; en este lugar se desarrolla buena parte de la vida, ya que las ceremonias familiares como velaciones se realizan ahí, en algunas ocasiones en las enramadas se cuenta con un pequeño horno de adobes para hacer el pan.

La etnia mayo, forjó con ingenio sus viviendas con elementos constructivos y a partir de ellos, fueron descubriendo la capacidad para tener más seguridad en los espacios que diseñaron para vivir. Así, fueron formando su hábitat confiados en la resistencia de los materiales que la misma naturaleza les proveía. 


\section{CONCLUSIONES}

\section{Universo observado.}

La casa mayoam se construye con diversos materiales que en ocasiones se combinan a pesar de sus diferencias de origen; existe un tipo de casa hechas con carrizo o corazón de pitahaya o sahuaro enjarrado de adobe; las estructuras están fijos a horcones de mezquite; en ocasiones el techo mismo es una estructura de madera y carrizo con emplastes de tierra y otra utilizan plástico industrial para impermeabilizarla.

Otro tipo de construcción se basa en el uso del adobe, el cual enjarran y encalan para evitar que lo destruya el salitre que en algunas comunidades normalmente las casas tienen una gran ramada hecha con postes de mezquite y techada con carrizo, tule o palma, según la región; en este lugar se desarrolla buena parte de la vida, ya que las ceremonias familiares como velaciones o cabos de año se realizan ahí, en algunas ocasiones en las enramadas se cuenta con un pequeño horno de adobes para hacer el pan, así como la toma de agua, el lavadero y el tendedero; a veces la gente duerme ahí en catres de tijera.

Es de considerar que la desafortunada ventaja del también abandono de estos pueblos alejados del "progreso" han permitido que muchas construcciones de la arquitectura vernácula de la etnia conserven aún los valores ancestrales en sus procedimientos constructivos y uso de elementos materiales, así se advierte en la hibridación y uso de los sistemas a base de una "estructura" de horcones de madera de mezquite para soportar la techumbre de troncos y morrillos de madera de mezquite y soportería de corazón de pitahaya terminando la cubierta con terrado (adobe). En este caso, como existen muchos de ellos, el muro está construido a base de adobe sin cocer y cumpliendo la función de muro divisorio aunada a la capacidad que como masa térmica se opone a la transmisidad de los inclementes rayos solares directos.

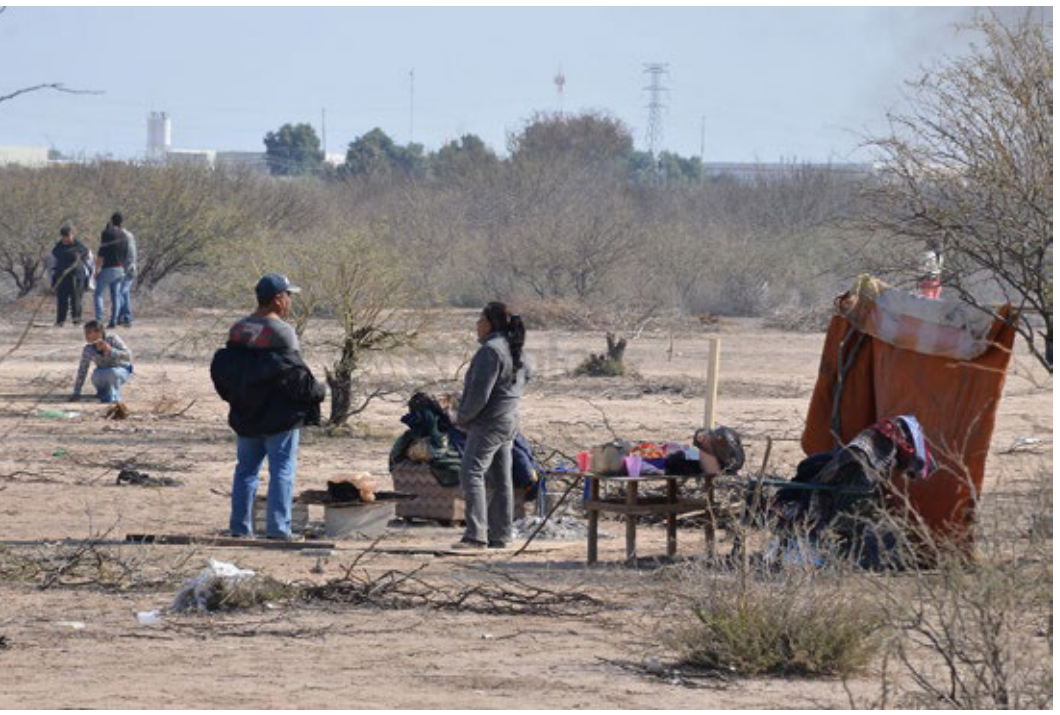

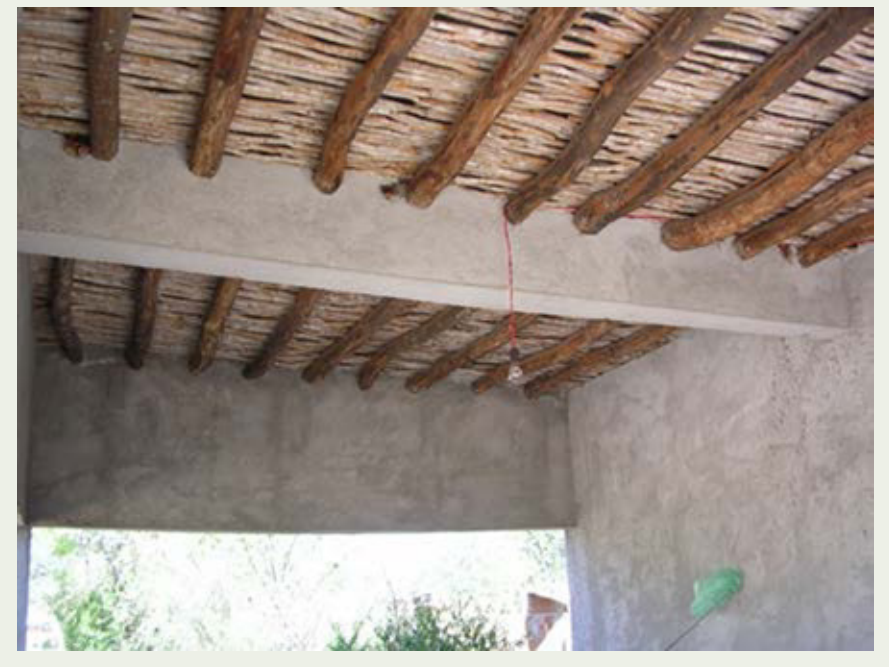

Fíg.9.- En el poblado de Masiaca, se aprecia la trabe de concreto dividiendo el espacio interior y permite que los morrillos no mayores de $3.00 \mathrm{~m}$ y diámetro de $15 \mathrm{~cm}$., conserve el carácter regional con la tradición vernácula mayo.

Propiedad del autor. 2004

En forma reiterativa se ha mencionado la solución y formas que se adoptaban para realizar las techumbres de las viviendas, estas, se soportan mediante vigas o troncos de mezquite, amapa, u otro propio de la región y con solo una forma de soportarlo y esta con media caña de pitahaya, varejones o carrizos colocados transversalmente sobre los morrillos y posteriormente se colocaba el terrado que es una capa de tierra inorgánica de espesor variable donde y hasta después de la llegada de los españoles se adopto la técnica de colocar una capa de mortero cal y arena en un proceso llamado bruñido que servía para evitar la filtración de agua y dar los declives para el escurrimiento de agua de lluvia. Cuando los modelos mestizos deseaban engrandecer la altura de la construcción, se procuraba desaguar la techumbre por medio de gárgolas de metal o piezas de piedra labradas.

El concepto de puerta en la arquitectura vernácula Mayo, no fue considerado como parte integral de su vivienda ya que solo en alguna condiciones climáticas se hacía necesario colocar alguna para cerrarla con una manta, lámina o madera, permitiendo el paso del aire. Al parecer su forma de convivencia y respeto a la propiedad ajena era considerada por las costumbres como de gran cuidado. $Y$ en ellos vemos como las viviendas tanto como sus predios no son espacios cerrados físicamente. Ahí se encuentran sus pertenencias y no están preocupados por perderlas.

Seguramente un análisis mas detallado nos hubiera permitido deslindar las ventajas de las características de los diseños de la vivienda vernácula de los mayoam y no 
solo nos brindara la oportunidad de satisfacer la curiosidad del efecto del humo de las cocinas dentro de las zonas habitables, deseable hubiera sido, establecer la velocidad y efectos de diferencia de temperatura hacia el interior de la habitación cerrada atendiendo la reducida dimensión de la ventana y del espacio cubierto porticado en referencia directa a la dimensión de las aberturas de paso y de las puertas, así como la geometría de los elementos estructurales de muros y postería (horcones), así como el papel que juega la forma de la techumbre que como ala de avión se perfila para romper y modificar la trayectoria del viento.

Desde la noción de tipología y los conceptos de Joseph María Montaner (2015) se nos orienta en la interpretación de las bases de la arquitectura hacia el espacio, pero aún en este espacio funcional, distributivo, constructivo $y / o$ matemático, la consonancia con el estructuralismo señala, que la esencia de las formas arquitectónicas estriba en los modos de la estructuralidad del espacio. Se trata paradójicamente de un estructuralismo que es a la vez historicista. Una de las partes más importantes de la adaptación de una construcción a un lugar y al entorno, se juega en las características de la piel, donde el objetivo sería no hacer una fachada unívoca sino plural que conduzca a una aplicación del contenido a la situación actual de la arquitectura, posiblemente, para cualificándola y explicando los contenidos dados en ella develen que "El problema de la arquitectura es que está en coordinación entre figura y concepto; es a nivel espacial de habitar, de utilizar, del mirar que nos sumamos a la apreciación que, por una fachada plana, así como lo entiende Joseph Muntañola (---) de un concepto con alto contenido figurativo.

Si se asume la visión del principio metodológico establecido por Claude Levi Strauss (1974), que lejos de que la búsqueda de inteligibilidad culmine en la historia como su punto de llegada, es la historia la que sirve de punto de partida para toda búsqueda de inteligibilidad. Por lo que se puede advertir que en la vivienda vernácula, el uso de materiales renovables y/o reciclables, reproduciéndose en

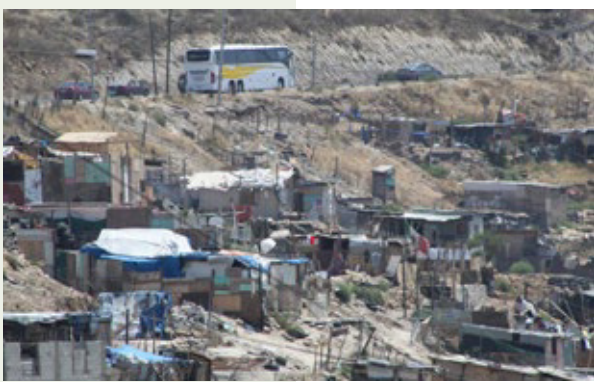
una baja escala que, al término de su vida útil, éstos se integran al ecosistema natural sin alterar los modos de vida.

También en los patrones tradicionales, se ofrecen expectativas a largo plazo coherentes a la protección del medio ambiente y depende exclusivamente de la economía local o regional con la utilización sólo de sus propios insumos e forma individual o colectiva su ejecución local, existiendo siempre, la participación del usuario y/o de la comunidad. La forma se explica por el clima y la necesidad de cobertura. Los materiales, la tecnología y el lugar; así como por cuestiones sociales que se relacionan con la economía, la defensa y la religión. Los materiales no determinan la forma por sí mismos, pues existen distintas formas realizadas con los mismos materiales y, tanto los materiales como las técnicas de construc-

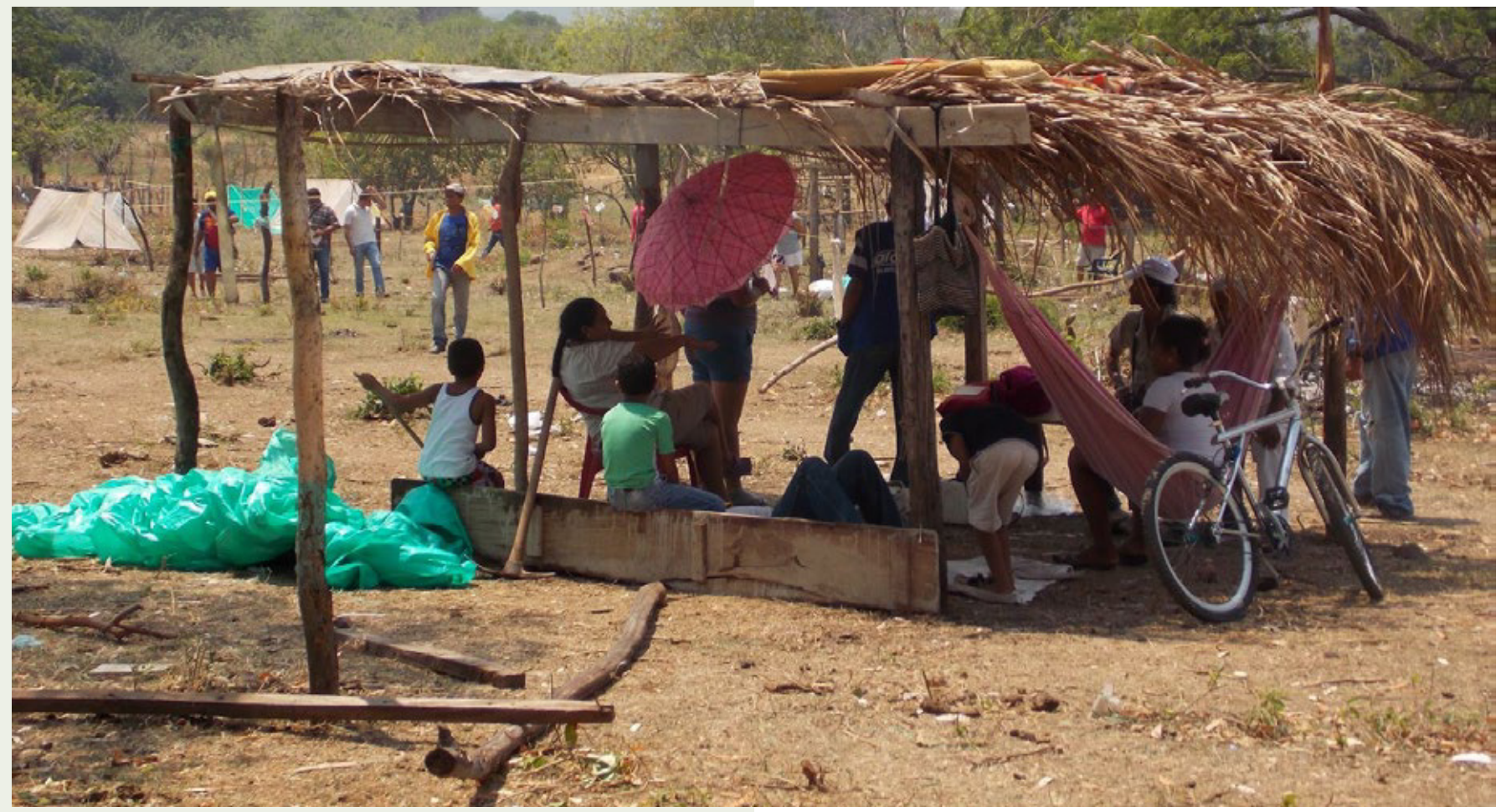


ción elegidas, influenciarán en la forma más no la determinarán, pues únicamente posibilitan modelos de vivienda rural y conocimientos empíricos de construcción que han sido seleccionados sobre otras bases, como las siguientes:

1. Es realizada con materiales de la zona, sin influencias contaminantes.

2. Los volúmenes primordialmente son rectangulares con líneas rectas que dominan en la antigua arquitectura vernácula.

3. Los primeros colonizadores tenían un legado cultural mediterráneo, influenciaron, aunque de manera mínima a la indígena, derivado de la ausencia de construcciones anteriores a la colonización y se manifiesta sobre todo en los jacales.

4. Los materiales utilizados han sido: varas, carrizos, barro, palma, adobe, sillar, piedra de canto rodado, piedra brasa, terrados, vigas y/o troncos de mezquite.

5.- El ya mencionado deseo de alejarse del calor, pero además del polvo, llevó a construir pocas ventanas, siendo de dimensión pequeñas y altas, o en ocasiones, tan grandes como puertas, enmarcándolas utilizando molduras, cornisas, pilastras, montantes y medias muestras, éstas últimas hechas con el fin de enmarcar esquinas, límites o entradas en las fachadas de los edificios, utilizando también, remates, balaustradas e inscripciones de fechas, años e iniciales influenciados por los colonizadores. Los pretiles altos vendrán a ser una respuesta más al calor dela región, con ellos se logra sombrear una mayor superficie de la cubierta, disminuyendo temperatura interior. Éste es un fenómeno social con una paradoja interesante; este fenómeno ha sido temido y anhelado por la sociedad. Temido, porque pone a prueba la firmeza con la que las edificaciones fueron construidas y las reta a seguir en pie; las reta a ser realmente el refugio de la vida, a luchar una batalla contra la naturaleza; y anhelado, porque es una de las únicas fuentes generadoras de lluvia.

6.- Los muros exteriores se recubren con un aplanado de arena, cal y/o arcilla. El acabado se realiza rústico, liso, aborregado o combinación de ambos. Los aplanados con dibujos geométricos, motivos vegetales y otros, simulando aparejos de sillar o almohadillado. El acabado aborregado en las paredes es una manifestación del deseo de protección contra el clima, pues "quiebra los rayos solares disminuyendo la temperatura interior, incorpora juegos de luz y sombra en los paños donde se incluye".

\section{BIBLIOGRAFÍA}

[1] Címbranos, F., D. H. Montesinos y M. Bustelo. El análisis de la realidad. En La Animación socio-cultural: una propuesta metodológica. España 1999. (23-55).

[2] Carlos Castañeda, Una realidad aparte. Las enseñanzas de don Juan. Fondo de Cultura Económica. próls. de Octavio
Paz y Walter Goldschmidt; trad. de Juan Tovar-2a ed. México: FCE, 2000

[3] Chávez, Oscar. Publicado en la revista "Ciudades" Frontera note de México: procesos territoriales. $\mathrm{N}^{\circ} 118$, abril-junio de 2018.p.2

[4] Diccionario Enciclopédico Larousse. 2002.

[5] Diccionario Larousse Conciso llustrado, 2002, p 774

[6] Figueroa, Alejandro, Por la Tierra y por los Santos, Culturas Populares de México, 1994

[7] Gobierno del Estado de Sonora.

[8] Pag.Web::www.sonora.gob.mx/conoce-sonora/documento publicado el 20 de noviembre de 2014

[9] Heidegger, Martin (1951) Construcción, Habitación, pensamiento. Ediciones del Serbal, España 1994

[10] J. H. Lambert. Nuevo Organón. Edic., de Geo Siegwart. Meiner, Hamburgo, 1988

[11] Paul Ricoeur Narratividad, fenomenología y hermenéutica. Gabriel Aranzueque, Ed., Madrid, España, 1997

[12] Levi-Strauss, Claude. Antropología Estructural librairie Plon, Paris (c) de todas las ediciones en castellano. Ediciones Paidós, S.A. Mariano Cubí, 92 -08021 Barcelona y Editorial Paidós, SAICF, Defensa, 599 - Buenos Aires. 1958 y 1974

[13] Martí Arís, Carlos (1993). Variaciones de la identidad, ensayo sobre tipo en arquitectura. Ediciones del Serbal.

[14] Norberg-Shultz, Christian. Anthropologie structurale. 12a reimpresión. 1958 y 1974, librairie

[15] Montaner Joseph María. La condición contemporánea de la arquitectura. Cultura, tipología y memoria urbana. P 40 ed. Gustavo Gili, México. 2015

[16] Pierre Bourdieu y Norbert Elías: Los conceptos de campo social y hábitus." www.redalyc.org, Consultada 30 diciembre de 2014

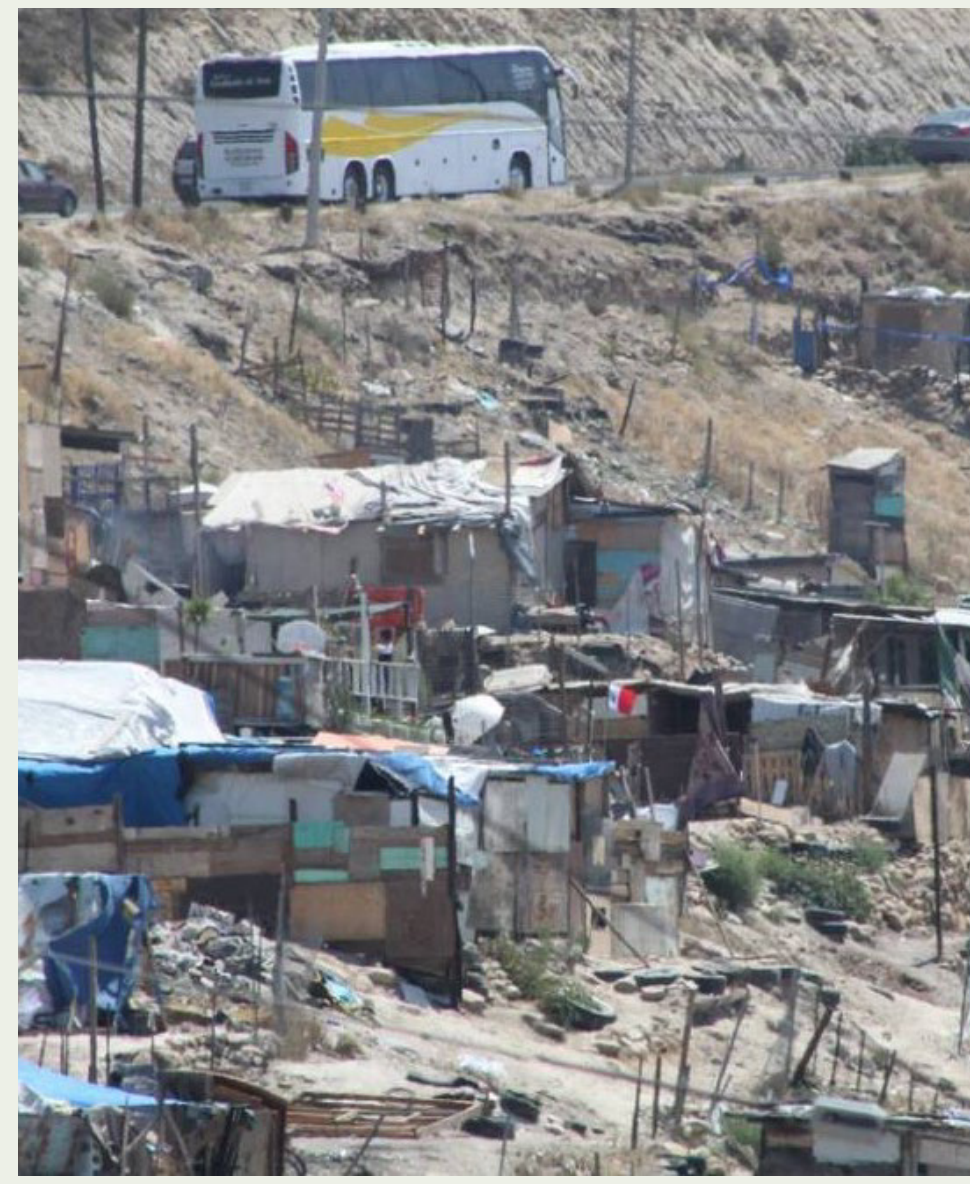

